\title{
A Brief Discussion on the Origin and Diachronic Evolution of the Sentence Pattern "Even If p, q" in Chinese*
}

\author{
Xiaoyan Cao \\ School of Literature \\ South China Normal University \\ Guangzhou, China
}

\begin{abstract}
The Chinese sentence pattern "even if $\mathrm{p}, \mathrm{q}$ " originated from the "although $p, q$ " format used in the Spring and Autumn Period. Then over a long-term development and change, there have successively been "if $p, q$ ", "even though $p$, $q$ ", "even if $p, q$ " and other sentence patterns. It was initially formed in the late Ming Dynasty, fully developed in the Qing Dynasty and widely used in the period of the Republic of China.
\end{abstract}

Keywords-concessional complex sentence; "even if p, q"; origin; evolution

\section{INTRODUCTION}

Concessional complex sentence is a manner to set aside modifier clause and let the main clause to state the result produced under such concessional condition ${ }^{1}$. "Even $\mathrm{p}, \mathrm{q}$ " a representative format of concessional complex sentences and has the semantic features of concession, virtuality and turning. The preceding clause prefixed by "even" represents the meaning of assumption and concession and the followed clause has the adversative meaning.

\section{ORIGIN OF THE ChINESE SENTENCE PATtern "Even IF P, Q"}

In ancient Chinese, there were many other "even if" and the like expressions representing concession and assumption such as "although, if, even if, even, even though, though" and the main clause may be connected by "also, moreover, generally" and so on. It is supposed that the Chinese sentence pattern "even if $\mathrm{p}, \mathrm{q}$ " originated from the "although $\mathrm{p}$, also q" format used in the Spring and Autumn Period and the Warring States Period. In this format, "although" is a conjunction, representing the meaning of "even if"; "also" is an adverb, representing the meaning of "still"; and the two clauses form a grammatical relationship between concessions and turning. For example, "Who said that you have not married yet? Why did you put me in jail? Even if I am jailed, you also can't marry me!" (See "The Book of

*One of preliminary research results of the Hongwu Weng Original Research Fund of Peking University; The research of Modern Chinese complex sentences' symmetrical-use linking words ( Project No.WHW201809)

Zhang Bin. Descriptive Grammar of Modern Chinese [M] Beijing: The Commercial Press, 2015:686.
Songs"). "At present, Jin State is lack of virtue. The captured female prisoners are settled in and made a pet of the State; then even if Jin State has been a strong country for many years, then what?" (See "Mandarin"). "Please promise me to manage affairs of the State. So even if I am dead, there is nothing to regret." (See "The Commentary of Zuo"). In the above three examples, the former clause connected by "even if" representing an assumption and concession and the latter clause connected by "also" representing the adversative meaning. The "although $\mathrm{p}$, also $\mathrm{q}$ " format indicates the grammatical relationship between concession and turning. Therefore, the "although p, also q" format used in the Spring and Autumn Period and the Warring States Period can be regarded as the origin of the Chinese sentence pattern "even if $\mathrm{p}, \mathrm{q}^{\prime \prime}$.

During the Spring and Autumn Period and the Warring States Period, there were also sentence patterns such as "in case that $\mathrm{p}$, also q". The conjunction "in case that" has the meaning of "if" and "assumption"; the adverb "also" has the meaning of "as well". The former and latter clauses form the grammatical relationship between concession and turning. For example:

(1) Duke Qi said, "If official approves (this matter), it is also my will; if he does not approve (this matter), you can also see him. (See "Battle of An" in "The Commentary of Zuo")

(2) If Chu State doesn't leave after I let the king make way for the officials, then Chu State is in the wrong. (See "Wengong Saved Song State and Defeated Chu State in Chengpu" in the "Mandarin")

(3) Those who have the sense of humiliation can be humiliated. His stable state can be shaken by humiliating him. If he does not know humiliation, he is certainly unaware of how to stick to the routine. (See "Entertainer Shi edifies Li Ji" in "Mandarin")

In the examples (1), (2) and (3), the concession represented by the clause connected by "if" is a virtual concession and is a concession to the virtual situation. In example (1), the clause connected by the conjunction "if" indicates a concession to the virtual situation that "Jin State 
does not agree to engage with Qi State." In example (2), the clause connected by the conjunction "if" indicates a concession to the virtual situation that "Chu State doesn't leave after I ( $\mathrm{Zi} \mathrm{Fan)} \mathrm{let} \mathrm{the} \mathrm{king} \mathrm{make} \mathrm{way} \mathrm{for} \mathrm{the} \mathrm{officials".}$ In example (3), the clause connected by the conjunction "if" indicates a concession to the virtual situation that "one does not care about humiliation."

During the Eastern Han Dynasty, the sentence pattern "even though p, also q" appeared and has the meaning of "even if $\mathrm{p}, \mathrm{q}$ ". For instance:

(4) Wherever people live, there is guest. Even though it is just different in size and yin and yang, even if they live in one room, they also have good and evil points. (See "Preface" of "The Yellow Emperor's House Theory")

During this period, the sentence pattern of "even though $\mathrm{p}$, also q" is not common and the mood of concession expressed by "even though" is slightly heavier than "even if".

During the Wei, Jin and Southern and Northern Dynasties, a sentence pattern of "even p, also q" appeared, representing "even if $\mathrm{p}$, also q". For instance:

(5) In the compassionate Temples and Pagodas built by you, these statues of gods all look powerful and sacred. Even though they are erected, fascinating, I am also happy. It is a pity that I can not worship together with you. (See "Collection of All Writings in Liang Dynasty".Vol.5)

During this period, the sentence pattern "even though $\mathrm{p}$, q" rarely appeared. "Even though" is used to strengthen the mood and "even" is more formal.

During the Sui, Tang, and Five Dynasties, there were "although (even/ even though) p, also q", "even if p, still q" sentence patterns, having the meaning of "even if $\mathrm{p}, \mathrm{q}$ ". For instance:

(6) Even if your nephew is talented, you must follow the rules to pay tribute. (See "Tongdian (Comprehensive Canon, a historical encyclopedia covering panoply of topics from high antiquity)". Vol.17)

(7) Chan master Weiren is taught by Chan master Xiu. So, even though he achieved Nirvana in the future, he cannot be listed as the six generations. (See "The Gods Quotations")

(8) If there is any culpable matter, although it is in virtue of other person, it is none of the business of the affiliated governor. (See "Datang Living Note")

(9) Even if the woman hears Mrs Zhou's teaching content, she still teaches her son to read hundreds of poems. She thinks that one may be dead before becoming a noble. (See "Dunhuang Change Works Collection". new version)

During this period, a variety of sentence patterns similar to "even if p, q" appeared. "Even though" connecting with a clause indicates an assumed concession, namely it has the same meaning as "even if" when a situation is put forward in the modifier clause. However, "even though" also has the meaning of "indulge and leave free" and "even if" does not have this meaning. "Though" and "even if" has the same meaning and don't have the meaning of "indulge and leave free".

In Song Dynasty, there was a sentence pattern of "even $p$, q", representing "even if p, q". For instance:

(10)Don't begin learning when teaching. It is not what you have heard. Even though you have ever heard, it cannot be used to conduct yourself properly. (See "Extensive Records of the Taiping Era". Vol. 57)

In Ming Dynasty, the "even p, q" sentence pattern appeared, wherein "even" has the meaning of "even if". For instance:

(11) Even he died, it is also needed to wait for about a year and then make decision based on your daughter's willingness. (See "Lasting Words to Awaken the World")

In Song Dynasty, the sentence pattern of "even p, q" appeared less frequently. In Ming Dynasty, the "even p, also q" sentence pattern also appeared less.

However in Qing Dynasty, there were "even p, and q", "though p, also q", "even if p, generally q" sentence patterns, having the meaning of "even if $\mathrm{p}, \mathrm{q}$ ". For instance:

(12) Regardless that brother can not cut firewood, though he can cut firewood, he cannot do like this. (See "Zhang Cheng" chapter in "Strange Tales of Liaozhai")

(13) Among them, even there may be part misinterpreted and modified by Liu Yin, it is not possible to be finished by only Liu Yin. (See "The Three Rituals" in the "General Theory of Confucian Classics")

(14) Lucid ganoderma grows everywhere, but people do not know it. Even they can know this grass, it may hide or reveal. Only the right person can eat it. (See "Xiuyun Loft", Ep 49)

(15) Even enemy dares to offend, It is not impossible to fend against it by dividing our forces. (See "The Wizard of Oz", Ep 31)

(16) Why don't I do like this? If I succeeded, I will not have a rough time on the way to Beijing any more; even I failed, it will also be better to obtain good food and drinks for several days. (See "Seven Heroes and Five Gallants", Ep 3)

(17) Even a girl is born, it is also necessary to get her married a scholar when she grows up. (See "Strange Tales of Swordswoman", Ep 26)

(18) Even they believe what we say, they may also send a document to the government of Sichuan to check it and it is wondered whether the government of Sichuan treats the case conscientiously or not. (See "The Wizard of Oz", Ep 19)

(19) Even though you are entangled or have little setbacks, it is always your destiny. Don't be discouraged and give up. (See "Eight Immortals", Ep 11)

(20) Fortunately, the imperial horse is found. Even though we fail to win his double hook, we can remake 
strategy try the best to take the horse back. (See "Case Records of Judge Shi", Ep 388)

(21) Even if you abide by rules and don't have any other intention, those don't know you may always say that you are not serious and know him personally. (See "Biography of Buddha Jih", Ep 59)

In this period, there were more sentence patterns similar to "even if $p, q^{\prime}$. Wherein, "even $p, q$ ", "even though $p$, always q" were often used in vernacular novels; "though $p$, and q" pattern is rarely used in Qing Dynasty. This phenomenon reflects that the language used in Qing Dynasty tended to become more colloquial.

In summary, the Chinese sentence pattern "even if $\mathrm{p}, \mathrm{q}$ " at first originated from the "although p, q" pattern stated in "The Book of Songs", where in "although" represents "even if" and the former clause connected by "although" and the followed clause are in concessional and turning grammatical relation.

\section{DiACHRONIC EVOLUTION OF THE SENTENCE PATTERN "EVEN IF P, Q" IN CHINESE}

The Chinese sentence pattern "even if $p$, q" has experienced a rather long diachronic evolution process which can be divided into three periods: formative period, development period and mature period.

\section{A. Formative Period: the End of Ming Dynasty}

The Chinese sentence pattern "even if $\mathrm{p}, \mathrm{q}$ " at first appeared in the Ming Dynasty novel "Astonishing and Miraculous Tales II" (Vol. 28): "Let alone the saying the couple jointly invited the snob to drink and the snob was willing to do this. Even if the snob is unwilling to do this, the couple can also beg for it step by step. How can they kill him? "In the "Astonishing and Miraculous Tales II", there is only one "even if $p, q$ " sentence pattern. Moreover, the sentence pattern "even if $\mathrm{p}$, q" also appeared in other literature of Ming Dynasty. For instance:

(22) He was so rude and treated me disrespectfully. Regardless that I am the local magistrate, even if we are equal in status, he should not do like this! (See "The Wonders of China". Vol.29)

(23) These poisons are not in sin, however even in the presence of the merciful kwan-yin bodhisattva, they must be killed while alive. (See "Marriages to Awaken the World", Ep 1)

(24) After all luckily Yu Mingwu came over to make a judgement and paid two or three ingots of money for fodders for those idle days; then even if it is to employee livestock in the future, don't count such ingots into to it. (See "Marriages to Awaken the World", Ep 5)

(25) If two among ten students went there, there may be 4 pairs; and even if eight students went there, there may be one pair remained. (See "Marriages to Awaken the World", Ep 33)

(26) This kind of heart is not good; even if you are going to marry her, you will have to wait for her finishing the funeral and then returning home to choose another lucky day. (See "Marriages to Awaken the World", Ep 42)

In the literature before and after Ming Dynasty, "even if $p$, q" pattern was used in 6 cases in total. Among them, one case appears in "Astonishing and Miraculous Tales II" and "The Wonders of China" and four cases appear in "Marriages to Awaken the World". Therefore, the end of Ming Dynasty is the formative period of the sentence pattern "even if $\mathrm{p}, \mathrm{q}$ ".

\section{B. Development Period: Qing Dynasty}

Up to Qing Dynasty, the "even if p, q" pattern is used more often than that in Ming Dynasty. This sentence pattern not only often appeared in the same ancient book but also often appeared in different ancient books. For example:

(27) At this time, Ren Dahai predicted that it is hard to win and what fills his mind is to kill both of them; so, even he is dead, it is equal. (See "Thirteen Heroes with Seven Swords", Ep 103)

(28) Being pushed around to such as situation, even if we don't do business, we have to fight for a breath, could we give up? (See "Notes of Emperor Qianlong's Southern Patrol", Ep 14)

(29) As for the clan, there are only the names of uncle and brother; even if the branch family is a little distant, they may also be called the $n$th brother in the family of the $i$ th uncle. (See "Strange Tales of Swordswoman", Ep 29)

(30) Even if the outcome is known and both of them are equal in match, they will inevitably be reprimanded by the founding master to avoid wasting time. (See "Eight Immortals", Ep 28)

(31) Please clam down, Madam. Even if I saved the prince, it is also the intrinsic business of me as a slave. (See "Generals of the Hu Family", Ep 22)

In Qing Dynasty, the sentence "even if $p$, q" was developed rapidly and its application is more than that in Ming Dynasty. The following "Table I" provides the examples of 15 ancient books written before and after this period, so as to fully explain the use of the sentence "even if $\mathrm{p}, \mathrm{q}^{\prime \prime}$ in the Qing Dynasty: 
TABLE I. The Use of the Sentence Pattern "Even If P, Q" IN Qing Dynasty

\begin{tabular}{|c|c|c|c|c|c|c|c|c|c|c|c|c|c|c|c|c|}
\hline $\begin{array}{l}\text { Book } \\
\text { name }\end{array}$ & \begin{tabular}{|c|} 
Zeng \\
Guofan \\
's \\
Letter \\
to \\
Family \\
\end{tabular} & \begin{tabular}{|c|} 
Thirtee \\
n \\
Heroes \\
with \\
Seven \\
Swords \\
\end{tabular} & 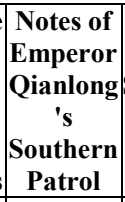 & \begin{tabular}{|c|} 
Strange \\
Tales of \\
Swordsw \\
oman
\end{tabular} & \begin{tabular}{|c|} 
Eight \\
Immortals
\end{tabular} & \begin{tabular}{|c|} 
The \\
Marriage \\
of \\
Flowers \\
in the \\
Mirror \\
\end{tabular} & \begin{tabular}{|c|} 
Case \\
Record \\
s of \\
Judge \\
Peng
\end{tabular} & \begin{tabular}{|c|} 
Case \\
Record \\
s of \\
Judge \\
Shi
\end{tabular} & \begin{tabular}{|c} 
Case \\
Record \\
s of \\
Judge \\
Di
\end{tabular} & \begin{tabular}{|c|} 
Romanc \\
e of Di \\
Qing
\end{tabular} & $\begin{array}{c}\text { Biograph } \\
\text { y of } \\
\text { Buddha } \\
\text { Jih }\end{array}$ & \begin{tabular}{|c|} 
The \\
Travel \\
s of \\
Lao \\
Ts'an
\end{tabular} & \begin{tabular}{|c|} 
Strang \\
e Tales \\
of \\
Liaozh \\
ai
\end{tabular} & \begin{tabular}{|c|} 
The \\
Schola \\
rs
\end{tabular} & $\begin{array}{c}\text { A Dream } \\
\text { in Red } \\
\text { Mansions }\end{array}$ & Subtotal \\
\hline \begin{tabular}{|l|l} 
Althoug & \\
h p, also \\
q
\end{tabular} & & 0 & 2 & 0 & 0 & 10 & 0 & 2 & 0 & 0 & 0 & 0 & 0 & 0 & 2 & 6 \\
\hline \begin{tabular}{|l|l} 
Even \\
though, \\
also q
\end{tabular} & 0 & 0 & 1 & 0 & 0 & 0 & 0 & 1 & 0 & 1 & 1 & 0 & 0 & 0 & 0 & 4 \\
\hline \begin{tabular}{l|l} 
Though & 0 \\
$\mathrm{p}$, also q
\end{tabular} & & 0 & 0 & 0 & 0 & 0 & 0 & 0 & 1 & 0 & 0 & 0 & 1 & 0 & 0 & 2 \\
\hline $\begin{array}{l}\text { Even ift } \\
\text { p, also q }\end{array}$ & & 10 & 7 & 1 & 1 & 18 & 0 & 10 & 0 & 0 & 0 & 0 & 1 & 0 & 0 & 52 \\
\hline $\begin{array}{l}\text { Even iffo } \\
\mathrm{p}, \mathrm{q}\end{array}$ & & 12 & 3 & 1 & 9 & 13 & 2 & 20 & 8 & 2 & 8 & 2 & 0 & 0 & 0 & 80 \\
\hline
\end{tabular}

\section{Mature Period: in Period of the Public of China}

Up to the period of the Public of China, "even if $p, q$ " pattern was more commonly used than that in Qing Dynasty and is more widely used. At that time, the application of this sentence pattern had entered a mature period. For example:

(32) Even if her family saw her, she would not avoid. (See "Ancient and Modern Anecdotes". Vol.2)

(33) The prefecture governor was extremely sorrowful and remorseful. He felt very sorry for his daughter even if he commited suicide. (See "Ancient and Modern Anecdotes". Vol.9)

(34) Even if people dare not say any joke about him, I am afraid that people may talk about him behind his back. (See "Divorcing Wife of Emperor Qianlong", Ep 2)

(35) I am hiding here. Even if I'm not taken by them, I will starve to death. (See "Romantic Records of Persons in Imperial Palace of Yuan Dynasty", Ep 5)
(36) Bro, my suffering cannot be made clear in a few words. Even if I can make it clear, it is useless to you as I have never met you before. (See "Knight-errant Picture of Emperor Yongzheng", Ep 16)

(37) Even if there was another joyful and sweet occasion, it might just be a temporary illusion. (See "Emperor Shunzhi Becoming a Monk", Ep 22)

During the Republic of China, a large number of vernacular novels emerged and the language used became more colloquial. Therefore, this situation creates a good external environment for the use of the "even if $p, q$ " sentence pattern to enter mature period.

The following "Table II" provides the examples of 15 ancient books written before and after this period, so as to fully explain the use of the sentence "even if $p, q$ " in the period of the Public of China:

TABle II. The Use of the Sentence Pattern “Even If P, Q" in Period of the Republic of China

\begin{tabular}{|c|c|c|c|c|c|c|c|c|c|c|c|c|c|c|c|c|}
\hline $\begin{array}{l}\text { Book } \\
\text { name }\end{array}$ & \begin{tabular}{|c|} 
Ancient \\
and \\
Modern \\
Anecdotes
\end{tabular} & \begin{tabular}{|l} 
Romantic \\
Records \\
of \\
Persons \\
in \\
Imperial \\
Palace of \\
Tang \\
Dynasty
\end{tabular} & $\begin{array}{c}\text { Battlefield } \\
\text { of Life } \\
\text { and Death }\end{array}$ & $\begin{array}{c}\text { Unofficial } \\
\text { History } \\
\text { of } \\
\text { Officials }\end{array}$ & \begin{tabular}{|c} 
Storm \\
and \\
Showers
\end{tabular} & Midnight & \begin{tabular}{|c|} 
The \\
Death \\
of \\
Yuli
\end{tabular} & \begin{tabular}{|l|} 
Fortress \\
Besieged \\
\end{tabular} & Wandering & \begin{tabular}{|l|} 
The \\
Border \\
Town
\end{tabular} & $\begin{array}{c}\text { Rickshan } \\
\text { Boy }\end{array}$ & \begin{tabular}{|c|} 
Tales \\
of \\
Hulan \\
River
\end{tabular} & \begin{tabular}{|l|} 
Cold \\
Night
\end{tabular} & $\begin{array}{c}\text { Guangling } \\
\text { Genre }\end{array}$ & \begin{tabular}{|c|} 
The \\
Mortal \\
Wind
\end{tabular} & Subtotal \\
\hline $\begin{array}{l}\text { Although } \\
\text { p, also q }\end{array}$ & & 0 & 0 & 0 & 0 & 0 & 0 & 0 & 0 & 0 & 0 & 0 & 0 & 0 & 0 & 10 \\
\hline \begin{tabular}{|l|} 
Even \\
though, \\
also q
\end{tabular} & 0 & 0 & 0 & 10 & 0 & 0 & 0 & 0 & 0 & 0 & 0 & 0 & 0 & 0 & 0 & 0 \\
\hline \begin{tabular}{|l|} 
Though \\
p, also q
\end{tabular} & & 0 & 0 & 0 & 0 & 0 & 0 & 0 & 0 & 0 & 0 & 0 & 0 & 0 & 0 & 0 \\
\hline \begin{tabular}{|ll} 
Even & iffo \\
p, also & q
\end{tabular} & & 1 & 0 & 0 & 0 & 0 & 0 & 0 & 0 & 0 & 0 & 0 & 0 & 0 & 0 & 1 \\
\hline \begin{tabular}{|ll} 
Even & if 5 \\
$\mathrm{p}, \mathrm{q}$ & \\
\end{tabular} & 56 & 1 & 0 & 0 & 1 & 15 & 10 & 1 & 6 & 0 & 19 & 0 & 1 & 5 & 6 & 111 \\
\hline
\end{tabular}

To sum up, the Chinese sentence pattern "even if $\mathrm{p}, \mathrm{q}$ " at first appeared in the "Astonishing and Miraculous Tales II" and was initially formed at the end of Ming Dynasty, scattered in the few (three) ancient books. In Qing Dynasty, 
this sentence pattern had been developed to a certain extent and had become more common in partial ancient books. During the Republic of China, this sentence pattern entered mature period and was widely used by more and more people.

\section{CONCLUSION}

The Chinese sentence pattern "even if $p$, q" originated from the "although p, also q" format used in the Spring and Autumn Period and the Warring States Period and at first appeared in the "Astonishing and Miraculous Tales II". The diachronic evolution of the Chinese sentence pattern "even if $\mathrm{p}$, q" has gone through a long period of time. It was formed in late Ming Dynasty, fully developed in Qing Dynasty and widely used in period of the Republic of China.

\section{REFERENCES}

[1] Ota Tatsuo. A Historical Grammar of Modern Chinese [M]. Beijing: Peking University Press, 2003. (in Chinese)

[2] Zhang Bin. Descriptive Grammar of Modern Chinese[M]. Beijing: The Commercial Press, 2010. (in Chinese)

[3] Zhou Gang. Conjunctions and related issues [M]. Hefei: Anhui Education Press, 2002. (in Chinese)

[4] Xing Fuyi. Research on Chinese Complex Sentences [M]. Beijing: The Commercial Press, 2001. (in Chinese)

[5] Yao Shuangyun. Research on the Collocation of Relation Markers of Chinese Complex Sentences[M]. Wuhan: Central China Normal University Press, 2008. (in Chinese)

[6] He Leshi et al. General Interpretation of Function Words in Ancient Chinese [M]. Beijing: Peking Publishing House, 1985. (in Chinese)

[7] Chi Changhai, Ling Yu. The Grammaticalization of the Concession Conjunction "even if" [J]. Journal of Jiangnan University (Humanities \& Social Sciences), 2008 (02). (in Chinese)

[8] Du Guoping. Logic Analysis of the Sentence Pattern of "Even if p, q" [J]. Zhejiang Social Sciences, 2011 (07). (in Chinese)

[9] Lv Mingchen, Tong Fuqi. Semantic Analysis of "Even..., ..." [J]. Seeker, 2012(01). (in Chinese) 